\title{
A Comparative Study of Adjustment and Happiness between Girls and Boys
}

\author{
Priyanka Agarwal ${ }^{1 *}$, Prerna Puri ${ }^{2}$
}

\section{ABSTRACT}

Adolescence is a transition period in which many changes take place. It may be physical, psychological or emotional changes. During this stage, they look for autonomy from their parents and like to take independent decisions with regard to their education, living matters, Future, career etc. The main objective of the study was to see the difference in adjustment and happiness of higher secondary school boys and girls. The sample consisted of 60 students (30 Boys, 30 Girls). Tests used were Subjective Happiness Scale of Lyubomirsky, S., \& Lepper, H. (1999) and Adjustment Inventory for school students (AISS) by A.K.P Sinha and R.P Singh (1971). After the data collection raw score were analysed using t test. Results revealed that the girls have a better adjustment than boys. There is a significant relationship between the total School adjustment of Girls and boys.

Keywords: Adjustment, Subjective Happiness, School students

Adolescence is a period of stress and storm that makes the adolescent to face many challenges in their life. It is a transition period during which they learn many new habits, behaviours and give up some old habits. They become an easy prey to emotional instability and may exhibit violent behaviours at home and at school due to lack of control in expressing views and opinions, lack of understanding their parents and teachers etc. All these pose a major threat to the positive development in adolescent school students.

Adjustment is a continuous life-long process. It is adaptation, achievement as well as process. It is a compromise between needs and circumstances. To live a happy and satisfied life adjustment is essential. It is harmonious relationship between the individual himself and the environment. During adolescence stage, many physical, psychological, behavioural, cognitive, emotional changes take place. Adolescents' shows strong feelings and intense emotions at different times.

\footnotetext{
${ }^{1}$ Research Scholar, Department of Psychology University of Rajasthan, Jaipur, India

${ }^{2}$ Associate Professor, Department of Psychology, University of Rajasthan, Jaipur, India

*Responding Author
}

Received: February 11, 2017; Revision Received: March 8, 2017; Accepted: March 10, 2017

(C) 2017 Agarwal P, Puri P; licensee IJIP. This is an Open Access Research distributed under the terms of the Creative Commons Attribution License (www.creativecommons.org/licenses/by/2.0), which permits unrestricted use, distribution, and reproduction in any Medium, provided the original work is properly cited. 


\section{A Comparative Study of Adjustment and Happiness between Girls and Boys}

Emotion is the current of energy that are within us. Emotion may be defined as the stirred up an organism involving internal and external changes in the body. Our emotions control our behaviour.

Emotion is a dynamic inner adjustment in the organism that operates for the satisfaction and welfare of the individual. Mood fluctuation appears during this stage. These emotional ups and downs can lead to increased conflict and adjustment problems among adolescents'. It becomes very difficult for the adolescents to cope up with these changes. There is a need to understand these problems faced by adolescents otherwise it would lead to mal-adjustment. Parent and teachers are more responsible for the emotional adjustment of the child. Therefore education of the adolescents must be planned in such a way enabling them to adjust personally, socially, emotionally and educationally to the various environments. The important area of adjustment as Home, Health, Social, Emotional and School Adjustment.

Happiness has been considered a major life goal in common philosophy (Anic \& Toncic, 2013). Happiness is defined as a multidimensional component of unconscious, cognitive, and motivational processes that are unique to how life is interpreted and received by individuals (Lyubomirsky, Tkach, \& DiMatteo, 2005). Previous research indicates that increased subjective well-being and happiness offers multiple benefits to individuals (Schiffrin \& Nelson, 2010). According to a study conducted on happiness among the college population, students believe that the core structure of happiness consists of high self-esteem, high self-confidence, social factors, occupational factors, and family factors (Crossley \& Langdridge, 2005). Nevertheless, college students face numerous barriers that impact their overall perceived happiness. Previous research has revealed that students who have high stress levels are less likely to report high perceived happiness (Schiffrin \& Nelson, 2010).

Happiness has been considered a major life goal in common philosophy (Anic \& Toncic, 2013). Happiness is defined as a multidimensional component of unconscious, cognitive, and motivational processes that are unique to how life is interpreted and received by individuals (Lyubomirsky, Tkach, \& DiMatteo, 2005). Previous research indicates that increased subjective well-being and happiness offers multiple benefits to individuals (Schiffrin \& Nelson, 2010). According to a study conducted on happiness among the population, students believe that the core structure of happiness consists of high self-esteem, high self-confidence, social factors, occupational factors, and family factors (Crossley \& Langdridge, 2005). Nevertheless, students face numerous barriers that impact their overall perceived happiness. Previous research has revealed that students who have high stress levels are less likely to report high perceived happiness (Schiffrin \& Nelson, 2010). 


\section{A Comparative Study of Adjustment and Happiness between Girls and Boys}

\section{Concept of School Adjustment}

Generally, adjustment implies the psychological processes that enable people to manage and cope with the demands and challenges of daily existence (Weiten and Lloyd, 1997). It connotes personal interaction with one's environment as mediated through social relationships and friendships. Within the school environment, the emphasis shifts to the well-being of students in different areas such as academic achievement and pro-social behaviours as seen in inter-personal relationships with fellow students and staff, and other school engagements like cocurricular activities (Wang, Chen, Sorrentino, Szeto, 2008). By implication, one has to change his or her behaviour to conform to the expectations required in a given environment. This is line with the Gehlawat (2011) concept of adjustment as a continuous process by which a person changes his own behaviour or tries to change the environment or brings changes in both to produce satisfactory relationship with his/her environment.

A satisfactory state of personal and emotional adjustment may be said to exist when an individual's physical and psychological needs can be satisfied by socially acceptable patterns of behaviour. Child's emotions exercise a potent influence upon his attitudes and behaviour. Unbridled emotional reactions may therefore, interfere seriously with young person's power to use the freedom of decision making and behaviour. Those students whose pattern satisfied with their life styles, whose urges and desires are met with satisfactions tends to enjoy life to the fullest and become emotionally adjusted.

Secondary school students' adjustment is a phenomenon that is of great concern to educationists as well as health practitioners. Educationists need to know what they can do to help their students adjust and benefit from school (Mizelle, 1999). Health practitioners on the other hand are concerned about the well-being of students (Knyazev, et al. 2002).

The study of Bhagat Pooja (2016) showed that female secondary school students are emotionally more adjusted as compared to male secondary school students. The high achiever secondary school students are emotionally more adjusted as compared to low achiever secondary school students. The high Parent-child relationship students are emotionally more adjusted as compared to low parent-child relationship students.

Makwana \& Kaji (2014) conducted a study on Adjustment of Secondary School Students in Relation to their Gender. The result shows that there is no significant difference in Home, School and Emotional adjustment of boys and girls secondary school student. But there is significant difference in Social adjustment of boys \& girls secondary school students at 0.05 level. It means boys are Social adjustment better than girls.

School adjustment is a broad construct which consists of many different aspects such as academic achievement, school satisfaction, school engagement and pro social behavior. Well- 


\section{A Comparative Study of Adjustment and Happiness between Girls and Boys}

adjusted students usually value what they are learning, are positively involved in classroom activities and receive high grades. Kiuru, et al. 2009). Poor school adjustment leads to low academic achievement, behavioral problems, discordant educational aspirations and even school dropout. (Vasalampi et al. 2009; Raju \& Rahamtula 2007).The study of Oramah, Emmanuel U. (2014) shows that there is a significant gender differences in the school adjustment of senior secondaiy school adolescent students.

Basu (2012) conducted a study on Adjustment of Secondary School Students .The findings of the present study reveal that there exist highly significant differences between the adjustment of secondary school students when compared on the basis of gender, type of family structure and medium of instruction in school. Chauhan (2013) conducted a study on study on adjustment of higher secondary school students of durg district. The t-test results indicate that there is significant difference in adjustment of higher secondary school's students and female students have good adjustment level when compared to the male students.

Research on gender differences in school adjustment has portrayed that girls are better adjusted as compared to boys. This has been evident in studies from the east and west. One such study was by Wang et al. (2008) who used a sample of 390 students in their study. They looked at uncertainty orientation in Chinese children: Relations with school and psychological adjustment and found that girls had higher scores on academic achievement, distinguished studentship and self-perceptions and lower scores on teacher rated learning problems than boys. Uncertainty orientation was significantly and positively associated with academic achievement, teacher-rated school competence and self-perceptions of competence. It was also significantly and negatively associated with teacher rated learning problems and loneliness. Another study in which girls performed better than boys was by Prakash and Coplan (2007) who used a sample of 929 children out of which $62.4 \%$ were males while 37.65 were females. They studied the socio emotional characteristics and school adjustment of socially withdrawn children in India. They found that boys were rated with lower academic scores than girls. $\mathrm{F}(1,545)=13.75, \mathrm{p}<.05$. (M $=3.23, \mathrm{SD}=.94$ compared with $(\mathrm{M}=3.60, \mathrm{SD}=.88)$. the studies by Wang et al (2008), Prakash and Coplan (2007) and Kiuru et al (2009) are based on student populations where girls achieve better academically, the current study seeks to find out the scenario in a situation where boys achieve better academically.

Gender differences in mean scores of happiness in this study, as perceived by adolescents living in socio-economic hardship revealed that the female adolescents perceived more happiness as compared to male adolescents. Argyle and Lu (1990) also documented that females reported significantly higher scores in happiness. On the contrary, Francis et al (1998) reported significantly higher scores among males in happiness. Findings are also inconsistent with the results indicated by Mehon et al (2005) that there were no significant gender differences in happiness between adolescent boys and girls. 
A Comparative Study of Adjustment and Happiness between Girls and Boys

\section{Objective}

1. To study the difference in adjustment and happiness of higher secondary school boys and girls.

\section{Hypotheses}

1. There will be no difference in adjustment and happiness of higher secondary school boys and girls.

\section{METHODOLOGY}

\section{Sample}

1. For the Present study 30 boys and 30 girls were selected of the class XI Commerce stream from higher secondary school of Jaipur district.

2. The sample is collected from the senior secondary class.

\section{Tool used}

1. “Adjustment Inventory for school students" (AISS) (1971) constructed by A.K.P.Sinha and R.P.Singh with 60 items equally distributed on Emotional, Social, Educational adjustments was used.

2. Subjective Happiness Scale of Lyubomirsky, S., \&Lepper, H. (1999) measures the happiness.

\section{Analysis of data and results}

The analysis of data and its interpretation is presented below. The results are shown in the following tables,

Table 1 Table showing ,t" value of School adjustment between Girls and boys.

\begin{tabular}{|l|l|l|l|l|l|l|}
\hline Variable & Gender & N & Mean & t & Level of significance \\
\hline \multirow{3}{*}{ School Adjustment } & Boys & 30 & 17.13333 & 2.507495 & $\begin{array}{l}\text { Significant at .01 } \\
\text { level }\end{array}$ \\
\cline { 2 - 4 } & Girls & 30 & 12.86667 & & \\
\hline
\end{tabular}

The table-1 Shows that the obtained „t" value of School Adjustment is greater than the table value (2.5074) at 0.01 significant level. Hence the null hypothesis is rejected. It is thus inferred that there is significant Difference between the total Adjustment of Girls and Boys.

Table 2 Table showing „t" value of happiness between Girls and boys.

\begin{tabular}{|l|l|l|l|l|l|}
\hline Variable & Gender & $\mathbf{N}$ & Mean & T & Level of significance \\
\hline \multirow{3}{*}{ Happiness } & Boys & 30 & 4.058333 & \multirow{2}{*}{4.08317} & $\begin{array}{l}\text { Significant at .01 } \\
\text { level }\end{array}$ \\
\cline { 2 - 4 } & Girls & 30 & 4.933333 & & \\
\hline
\end{tabular}

(c) The International Journal of Indian Psychology, ISSN 2348-5396 (e) | ISSN: 2349-3429 (p) | 133 


\section{A Comparative Study of Adjustment and Happiness between Girls and Boys}

The table-2 Shows that the obtained „„te value of Happiness is greater than the table value (4.08317) at 0.01 significant level. Hence the null hypothesis is rejected. It is thus inferred that there is significant Difference between Happiness of Girls and Boys.

\section{DISCUSSION}

Adjustment is a continuous life-long process. It is adaptation, achievement as well as process. It is a compromise between needs and circumstances. To live a happy and satisfied life adjustment is essential. It is harmonious relationship between the individual himself and the environment. The aim of to study the difference in adjustment and happiness of higher secondary school boys and girls.

The table-1 Shows that the obtained ,te value of School Adjustment is greater than the table value (2.5074) at 0.01 significant level. Hence the null hypothesis is rejected. It is thus inferred that there is significant Difference between the total Adjustment of Girls and Boys. The Mean Value shows that Girls has a greater School Adjustment than boys. Basu (2012) conducted a study on Adjustment of Secondary School Students .The findings of the present study reveal that there exist highly significant differences between the adjustment of secondary school students when compared on the basis of gender, type of family structure and medium of instruction in school.

The studies by Wang et al (2008), Prakash and Coplan (2007) and Kiuru et al (2009) are based on student populations where girls achieve better academically, the current study seeks to find out the scenario in a situation where boys achieve better academically.

The table-2 Shows that the obtained " $t$ " value of Happiness is greater than the table value (4.08317) at 0.01 significant level. Hence the null hypothesis is rejected. It is thus inferred that there is significant Difference between Happiness of Girls and Boys. The Mean Value shows that Girls are happier than boys. May be the girls have a better school adjustment so their happiness is more. The study of Neha Sharma, Jatinder Kaur Gulati (2015) shows that females perceived more happiness as compared to male adolescents. Gender differences in mean scores of happiness in the study, as perceived by adolescents living in socio-economic hardship revealed that the female adolescents perceived more happiness as compared to male adolescents. Argyle and Lu (1990) also documented that females reported significantly higher scores in happiness.

\section{CONCLUSION}

On the basis of present study it can be concluded that there is a significant Difference between the total School adjustment and happiness of Girls and Boys. Students who have good adjustment are happier than those who have adjustment problem. 


\section{A Comparative Study of Adjustment and Happiness between Girls and Boys}

\section{Acknowledgments}

The author appreciates all those who participated in the study and helped to facilitate the research process.

Conflict of Interests: The author declared no conflict of interests.

\section{REFERENCES}

Anic, P., \& Toncic, M. (2013). Orientation to happiness, subjective well-being and life goals. Psychological Topics, 22(1), 135-153.

Argyle M, Lu L.(1990) Happiness of extraverts. Personality and Individual Differences,11,101117.

Basu, S. (2012). Adjustment of Secondary School Students. An International peer reviewed Scholarly Research Journal for Interdisciplinary Studies, 1, 3.

Bhagat P.,(2016) Comparative Study of Emotional Adjustment of secondary school students in relation to their gender, Academic Achievement and parent child Relationship. International Journal of Recent Scientific Research, 7 (7),12459-12463.

Chauhan. (2013). A study on adjustment of higher secondary school students of durg district. IOSR Journal of Research \& Method in Education, p-ISSN: 2320-737X , 1, (1), 50-52.

Crossley, A., \& Langdridge, D. (2005). Perceived sources of happiness: A network analysis. Journal of Happiness Studies, 6(2), 107-135.

Francis L.J., Lewis, J.M., Philipchalk R., Brown, L.B., Lester, D. (1998).The inter consistency reliability and construct validity of the Francis scale of altitude towards Christianity (adult) among undergraduate students in the United Kingdom, United States, Australia and Canada. Personality and Individual Differences; 19,949-53.

Gehlawat, M. (2011). A Study of Adjustment among High School Students in relation to their Gender, International Referred Research Journal, 3 (33).

Kiuru, N., Nurmi J., Aunola K., Salmela, A.K. (2009). Peer group homogeneity in adolescents' school adjustment varies according to peer group type and gender. International Journal of Behavioral Development, 33 (1) 65-76.

Knyazev G. G., Slobodskaya H. R., Safronova M. V., \& Kinsht I. A. (2002). School adjustment and health in Russian adolescents. Psychology, Health and Medicine ,7 (2) $143-155$.

Lyubomirsky, S., Tkach, C., \& DiMatteo, M. R. (2005). What are the differences between happiness and selfesteem? Social Indicators Research, 78(3), 363-404.

M. E. P., Steen, T. A., Park, N., \& Peterson, C. (2005). Positive psychology progress: Empirical validations of interventions. The American Psychologist, 60, 410-421.

Makwana \& Kaji. (2014). Adjustment of Secondary School Students in Relation to their Gender. The International Journal of Indian Psychology, 2, 1.

Mizelle N. B. (1999). Helping middle school students make the transition into high school. CEEP Archive of ERIC-EECE Digests.

(c) The International Journal of Indian Psychology, ISSN 2348-5396 (e)| ISSN: 2349-3429 (p) | 135 


\section{A Comparative Study of Adjustment and Happiness between Girls and Boys}

Oramah, Emmanuel U.(2014) Gender Differences in the School Adjustment of Senior Secondary School Adolescent Students in Delta North Senatorial District of Delta; State, Gender \& Behaviour, 12,1.

Prakash, K. \& Coplan, R.J. (2007). Socioemotional characteristics and school adjustment of socially withdrawn children in India. The International Society for the study of behavioural development.

Raju, M. V. \& Rahamtulla, T. K. (2007). Adjustment Problems among School Students; Journal of the Indian Academy of Applied Psychology. 33 (1) 73- 79.

Schiffrin, H. H., \& Nelson, S. K. (2010). Stressed and happy? Investigating the relationship between happiness and perceived stress. Journal of Happiness Studies, 11(1), 33-39. Seligman

Sharma N, Gulati J, Gender differences in happiness, Self-esteem and personality traits in adolescents living in socioeconomic hardship, International Journal of Home Science 2015; 1(1): 18-25.

Vasalampi, K. Salmela-Aro K., Nurmi, J. (2009) Adolescents self concordance, school engagement, and burnout predict their educational trajectories. European psychologist, vol 14 (4)

Wang, Z., Chen, X., Sorrentino, R. \& Szeto, A. C. (2008). Uncertainty orientation in Chinese children: Relations with school and psychological adjustment. International Journal of Behavioral Development 32 (2) 137-144

Wong, K. S., \& Cheuk, W. H. (2005). Job-related stress and social support in kindergarten principals: The case of Macau. International Journal of Educational Management, 19(3), 183-196.

How to cite this article: Agarwal P, Puri P (2017), A Comparative Study of Adjustment and Happiness between Girls and Boys, International Journal of Indian Psychology, Volume 4, Issue 2, No. 93, ISSN:2348-5396 (e), ISSN:2349-3429 (p), DIP:18.01.134/20170402, ISBN:978-1365-78193-3 